\title{
Racismo cotidiano na política brasileira: xingamentos e ameaças contra a parlamentar negra Talíria Petrone e seu significado na herança colonial
} Daily racism in Brazilian politics: insults and threats against black
parliamentarian Talíria Petrone and its meaning in the colonial heritage Racismo cotidiano en la política brasileña: insultos y amenazas contra la parlamentaria negra Talíria Petrone y su significado en la herencia colonial

Carla Baiense Felix ${ }^{1, a}$

carlabaiense@id.uff.br | https://orcid.org/0000-0002-7287-6170

Monique Paulla ${ }^{1, b}$

paula.monike@gmail.com | https://orcid.org/0000-0002-0170-6617

${ }^{1}$ Universidade Federal Fluminense, Instituto de Arte e Comunicação Social, Programa de Pós-Graduação em Mídia e Cotidiano. Niterói, Rio de Janeiro, Brasil.

a Doutorado em Comunicação e Cultura pela Universidade Federal do Rio de Janeiro

b Mestrado em Mídia e Cotidiano pela Universidade Federal Fluminense.

\section{RESUMO}

As ameaças e xingamentos racistas direcionados à parlamentar Talíria Petrone, no exercício do seu mandato, expressam a especificidade dos riscos de adoecimento e morte que as mulheres negras enfrentam na política institucional. Partindo do reconhecimento desse fenômeno como uma realidade traumática, como demonstra Kilomba, analisamos os episódios de racismo cotidiano (idem), numa perspectiva interseccional, a partir de uma publicação da deputada no Instagram, e seu significado dentro da herança colonial escravagista brasileira. A análise corrobora a necessidade de plataformas que contemplem e governos que implementem ações efetivas para coibir este tipo de crime e assegurar os direitos políticos e a saúde plena dessas mulheres.

Palavras-chave: Racismo cotidiano; Trauma; Interseccionalidade; Talíria Petrone; Redes sociais.

\section{ABSTRACT}

The racist threats and insults against the parliamentarian Talíria Petrone, in the exercise of her mandate, express the specificity of the risks of illness and death that black women face in the institutional politics. Based on the recognition of this phenomenon as a traumatic reality, as Kilomba shows us, we analyzed the episodes of everyday racism, in an intersectional perspective, from a post published by the deputy in her In- 
stagram profile, and their meaning within the Brazilian colonial slavery heritage. The analysis corroborates there is a need for platforms contemplating and governments implementing effective actions to hinder this type of crime and to ensure the political rights and the complete health of these women.

Keywords: Everyday racism; Trauma; Intersectionality; Talíria Petrone; Social network.

\section{RESUMEN}

Las amenazas y los insultos racistas dirigidos a la parlamentaria Talíria Petrone, en ejercicio de su mandato, expresan la especificidad de los riesgos de enfermedad y muerte que enfrentan las mujeres negras en la política institucional. Apoyando en el reconocimiento de este fenómeno como una realidad traumática, como demonstra Kilomba, analizamos los episodios de racismo cotidiano, en una perspectiva interseccional, teniendo en cuenta una publicación en el perfil de Instagram de la diputada, y su significado dentro de la herencia de esclavitud colonial brasileña. El análisis corrobora la necesidad de que las plataformas contemplen y los gobiernos implementen acciones efectivas para cohibir ese tipo de crimen y asegurar los derechos políticos y la salud integral de esas mujeres.

Palabras clave: Racismo cotidiano; Trauma; Interseccionalidad; Talíria Petrone; Redes sociales.

Este artigo compõe o dossiê Feminismos: perspectivas em comunicação e informação em saúde, parte 1.

Contribuição dos autores:

Concepção e desenho do estudo: Carla Baiense Felix, Monique Paulla.

Aquisição, análise ou interpretação dos dados: Carla Baiense Felix; Monique Paulla.

Redação do manuscrito: Carla Baiense Felix, Monique Paulla

Revisão crítica do conteúdo intelectual: Carla Baiense Felix; Monique Paulla.

Declaração de conflito de interesses: não há.

Fontes de financiamento: não houve.

Considerações éticas: não há.

Agradecimentos/Contribuições adicionais: não há.

Histórico do artigo: submetido: 10 mar. 2021 | aceito: 9 jun. 2021 | publicado: 30 jun. 2020.

Apresentação anterior: não há.

Licença CC BY-NC atribuição não comercial. Com essa licença é permitido acessar, baixar (download), copiar, imprimir, compartilhar, reutilizar e distribuir os artigos, desde que para uso não comercial e com a citação da fonte, conferindo os devidos créditos de autoria e menção à Reciis. Nesses casos, nenhuma permissão é necessária por parte dos autores ou dos editores. 


\section{INTRODUÇÃO}

O feminicídio político da vereadora Marielle Franco (SOUZA, 2020), em março de 2018, expôs a grave ameaça à integridade física, mental e moral que as mulheres, sobretudo as pretas e periféricas, enfrentam nos espaços da política institucional. Nelas se sobrepõem opressões de raça e gênero, que se expressam em episódios de racismo cotidiano (KILOMBA, 2020) e interseccional (CRENSHAW, 1991). Kilomba analisa os efeitos desta realidade violenta em termos de trauma, "um choque violento que de repente coloca o sujeito negro numa cena colonial na qual, como no cenário de uma plantação, ele é aprisionado como a/o "Outro/a" subordinado e exótico" (2019, p. 30).

A política institucional brasileira se configura, historicamente, como um espaço de homens brancos, pertencentes a um número limitado de famílias. Neste sentido, o corpo das mulheres negras é lido como intruso, uma alteridade radical que rompe a membrana protetora desses espaços, acionando o medo branco de contágio e ameaçando a supremacia da branquitude hegemônica. O isolamento e a intimidação dessas mulheres, portanto, são alguns dos mecanismos mais eficazes de manutenção dessa ordem.

A baixa participação de mulheres negras na política institucional atesta a eficácia dessa estratégia. No ranking de participação feminina no Parlamento, elaborado pela ONU Mulheres em parceria com a União Interparlamentar (UIP), o Brasil ocupava a 154 a posição entre os 174 países analisados em 2017 (A REPRESENTAÇÃO..., 2018). Em 2018, com a eleição de 77 deputadas federais, a ocupação das mulheres no Parlamento subiu de 10\% para 15\%, mantendo o país entre os piores em equidade de gênero na América Latina e Caribe, onde as mulheres representam, em média, 28,8\% das cadeiras nas Câmaras de Deputados ou Câmaras Únicas (BANCADA..., 2018).

Quando se interseccionam gênero e raça, as diferenças se acirram. Apenas 13 das 77 mulheres eleitas para a atual legislatura brasileira se declaram negras, e uma única se reconhece como indígena. Essas mulheres, cujos corpos são lidos como impróprios para a política institucional, são cotidianamente lembradas que estão 'fora do lugar', uma realidade racista que, embora 'esperada', dada a configuração histórica brasileira, irrompe com tamanha intensidade e violência que produz cicatrizes psíquicas profundas, mas "amplamente negligenciadas" (KILOMBA, 2020, p. 72).

Neste artigo, analisamos como o racismo cotidiano se manifesta nas publicações feitas nas redes sociais da parlamentar negra Talíria Petrone. Selecionamos, para esta investigação, uma postagem feita pela deputada no seu perfil no Instagram no dia 18 de maio de 2019. Analisamos os sentidos produzidos nas ameaças e xingamentos contidos nessa postagem em termos de reatualização do passado escravagista, que aprisiona os sujeitos negros na cena colonial. Argumentamos, no final, que as plataformas e os governos precisam assumir sua responsabilidade diante da perpetuação do racismo, visto como uma realidade traumática, produtora de dor e adoecimento emocional.

\section{DOR E TRAUMA}

A ideia de trauma expressa originalmente um dano causado à pele por uma violência externa. Em termos psicanalíticos, refere-se a um evento violento ao qual uma pessoa não é capaz de responder adequadamente, porque excede os níveis toleráveis de excitação externa que seu aparato psíquico é capaz de tolerar.

Em sua tese de doutoramento, publicada em livro em 2008, a psicóloga e doutora em filosofia Grada Kilomba analisa o racismo a partir da perspectiva psicanalítica. Sua contribuição nos ajuda a pensar tanto na construção dos sujeitos negros como "a ameaça, o perigo", que permite "à branquitude olhar para si como moralmente ideal” (KILOMBA, 2020, p. 37), como nos aproxima da dor que a realidade traumática é capaz de causar a esses indivíduos objetificados. Ambos os processos acionam a dinâmica de lembrar e 
esquecer, na qual os sujeitos brancos se livram da culpa, ao expulsar do consciente a recordação do mal produzido aos povos escravizados, enquanto reiteram a dor desses povos, atualizando o racismo.

Quijano (2005) apresenta a racialização como o mecanismo fundamental adotado pelos europeus para legitimar a invasão, expropriação e exploração dos territórios e dos povos originários das Américas e da África. É em termos de raça e gênero (LUGONES, 2008) que essas populações são integradas à dinâmica colonial, fundada na hierarquização da diferença. Neste esquema, homens brancos representam a norma, enquanto pessoas negras e indígenas são o desvio. As mulheres, nesta lógica, são o desvio do desvio. A desumanização desses povos e, portanto, seu não pertencimento à sociedade, se constitui numa estratégia para possibilitar todo tipo de violência e opressão.

O racismo se apresenta como a rememoração dessa cena colonial, expropriando os sujeitos de sua identidade. Para Kilomba, "Tal separação é definida como um trauma clássico, uma vez que priva o indivíduo de sua própria comunicação com a sociedade inconscientemente pensada como branca” (KILOMBA, 202O, p. 39).

A autora enfatiza, ainda, o caráter cotidiano de tal violência, uma vez que o racismo não é apenas um episódio na vida de uma pessoa, mas uma realidade que irrompe no cotidiano dos sujeitos negros, sem que tenham feito nada para suscitar sua ocorrência. "[...] o acúmulo de eventos violentos que, ao mesmo tempo, revelam um padrão histórico de abuso racial que envolve não apenas os horrores da violência racista, mas também as memórias coletivas do trauma colonial” (KILOMBA, 2020, p. 215).

A resposta a este trauma se expressa tanto em termos psicológicos quanto físicos. Assim como Fanon, as entrevistadas de Kilomba e ela própria traduzem numa linguagem corporal a dor produzida pelo choque, que é o primeiro elemento do trauma. Sua primeira lembrança é a de vomitar depois de ouvir, ainda criança, a proposta de "limpar a casa" da família de um médico, após uma consulta. Uma das suas sujeitas de pesquisa, por outro lado, relata a dor nos dedos que sentia cada vez que era confrontada com a cena colonial. Fanon (2008), por sua vez, define a dor como lâminas cortando sua pele.

Para além dos sintomas físicos, a autora identifica a cicatriz psíquica produzida por essa realidade violenta e que tem sido negligenciada. Ela examina, por exemplo, como o suicídio de mulheres negras adquire um sentido performático, na medida em que dá concretude à invisibilidade dessas sujeitas numa sociedade pensada como branca. É a partir dessa perspectiva do racismo como um gesto violento, que traz à memória a cena colonial, que analisaremos as publicações nas redes sociais da parlamentar Talíria Petrone.

\section{POLÍTICA E RACISMO COTIDIANO}

O feminicídio político de Marielle Franco, em 2018, reacendeu a preocupação com a segurança física da parlamentar Talíria Petrone. Desde o seu primeiro mandato como vereadora de Niterói, cidade da área metropolitana do Rio de Janeiro, Talíria foi alvo de constantes gestos de violência e ameaças na tribuna e nas redes sociais digitais. Com a sua eleição para a posição de deputada federal, a política de medo, intimidação e violência foi ampliada pelo impacto da sua atuação.

Por isso, desde o início de seu mandato na Câmara de Deputados, em abril de 2019, a parlamentar precisou receber a proteção da polícia legislativa. A escolta policial foi suspensa devido ao isolamento social provocado pela pandemia do novo coronavírus (Sars-Cov-2), em 2020, e novamente retomada, naquele ano, após o serviço Disque-Denúncia identificar uma ameaça à vida da deputada. Atualmente, ela mora fora do estado do Rio de Janeiro, mantendo seu novo endereço sob sigilo.

Ao historicizar os riscos impostos à Angela Davis, descrita como "uma mulher negra revolucionária" (p. 11), a historiadora Raquel Barreto (2019) conta como a feminista recebia, nos anos 1970, ameaças de morte antes de falar. Respeitando as especificidades de cada tempo e lugar, vale lembrar que 50 anos depois ainda se verifica que falar é uma atividade de risco para as mulheres. 
Kilomba lembra que a máscara de ferro utilizada como castigo contra pessoas escravizadas também tinha literalmente a função de impedir que suas narrativas fossem enunciadas. É neste sentido que o ato de calar as parlamentares negras deve ser visto nesse contexto de negação de direitos e racismo, que atualizam a violência colonial. A vereadora Marielle Franco, em sua última fala na Câmara, no dia 8 de março de 2018, se colocou contra essa tentativa de silenciamento. "Não serei interrompida. Não aturo interrompimento dos vereadores desta casa. Não aturarei de um cidadão que vem aqui e não sabe ouvir a posição de uma mulher eleita" (FRANCO, 2018).

Talíria também foi alvo de tentativas de intimidação pelas redes sociais e ameaças de morte, incluindo a ameaça de explosão da sede do PSOL. Todos os casos foram registrados na $76^{\text {a }}$ Delegacia de Polícia da cidade de Niterói por meio de notícia-crime. A resistência dessas mulheres é entendida como uma afronta. "É como se o próprio ato da fala, no qual uma mulher conversa com um homem, carregasse um desafio, uma ameaça à dominação masculina" (HOOKS, 2019, p. 263). hooks nos chama a atenção para o fato de que "na sociedade patriarcal, o silêncio é para as mulheres um gesto de submissão e cumplicidade" (HOOKS, 2019, p. 262). E complementa afirmando:

Muitas vezes esse silêncio é aprendido quando somos apenas crianças. Muitas de nós fomos ensinadas que de nosso pai, porque era homem, não se podia falar, ou não se podia falar com ele, a menos que ele quisesse conversar com a gente, e então os pais nunca podiam ser abordados criticamente. (HOOKS, 2019, p. 262)

Lélia Gonzalez (1983) sinalizava para a função do estereótipo da "mulher negra atrevida", alimentado pela branquitude e atribuído às mulheres negras que ousavam falar nos seus próprios termos. O relato apresentado por Gonzalez, acerca de um evento de lançamento de um livro sobre a negritude, revela de maneira sarcástica as negociações em torno de quem pode falar/o quê/em que lugares:

A gente tinha que ser educado. E era discurso e mais discurso, tudo com muito aplauso. Foi aí que a neguinha que tava sentada com a gente, deu uma de atrevida. Tinham chamado ela prá responder uma pergunta. Ela se levantou, foi lá na mesa prá falar no microfone e começou a reclamar por causa de certas coisas que tavam acontecendo na festa. Tava armada a quizumba... Agora, aqui prá nós, quem teve a culpa? Aquela neguinha atrevida, ora. Se não tivesse dado com a língua nos dentes... (GONZALEZ, 1983, p. 223)

O fato de Talíria assumir o compromisso de ter uma fala libertadora gera o incômodo dos homens que controlam a política no cenário nacional, o que resulta em constantes ameaças de morte. Talíria relatou para a BBC Brasil o racismo cotidiano vivido na Câmara Municipal de Niterói. "[...] nunca sofri tanto racismo de forma explícita como na minha experiência de um ano (como vereadora). Desde ser chamada de negra nojenta, ouvir 'neguinha volta para senzala', 'que cabelo é esse?', até ameaças concretas de morte" (SCHREIBER, 2018).

Ao enfatizar o racismo cotidiano, não negamos os aspectos estruturais e institucionais que estão imbricados nas ameaças e xingamentos proferidos contra a deputada do Rio de Janeiro. Nos interessa compreender como tais aspectos se manifestam no dia a dia em "vocabulário, discursos, imagens, gestos e ações que colocam o 'sujeito negro' e as Pessoas de Cor” (KILOMBA, 2020, p. 78) como o outro nesses espaços de poder.

As violências racistas e sexista cotidianamente direcionadas à Talíria retroalimentam "as imagens de controle surgidas na era da escravidão que ainda hoje (são) aplicadas às mulheres negras” (COLLINS, 2019, p. 35). Ao mesmo tempo que reforçam as agressões no contexto sociocultural, também se aplicam ao contexto político, atualizando essas violências e esses estereótipos.

A manutenção das estruturas, linguagens e parâmetros das relações sociais do Brasil escravocrata são expressas nos crimes e agressões praticados contra a Talíria. Gonzalez (2020) nos ensina que "um dos 
meios mais eficientes de fugir da angústia é ridicularizar, é rir daquilo que a provocaprovoca” (p. 86). Observa-se, portanto, como as violências direcionadas à deputada têm por finalidade básica "deslegitimar o pleno exercício dos direitos de cidadania das mulheres negras" (p. 155) a partir das práticas racistas e misóginas performadas na política institucional.

Para analisar como se dão tais práticas e distinguir seu significado no imaginário colonial racista brasileiro, vamos analisar a postagem feita pela parlamentar na rede Instagram, no dia 18 de maio de 2019. A postagem traz um texto principal, da própria parlamentar, e uma série de prints contendo ameaças e xingamentos contra ela, publicados por figuras públicas e anônimas, no Twitter e no próprio Instagram. A análise será ancorada pelo pensamento feminista, sobretudo pelas contribuições das intelectuais negras.

\section{DISCURSO COLONIAL NO INSTAGRAM}

A deputada federal Talíria Petrone conta com 262 mil seguidores na rede social Instagram, considerando os números até março de 2021. No dia 18 de maio de 2019, ela fez uma postagem denunciando as mensagens criminosas que vinha recebendo pelas redes sociais, como exposto na figura 1.

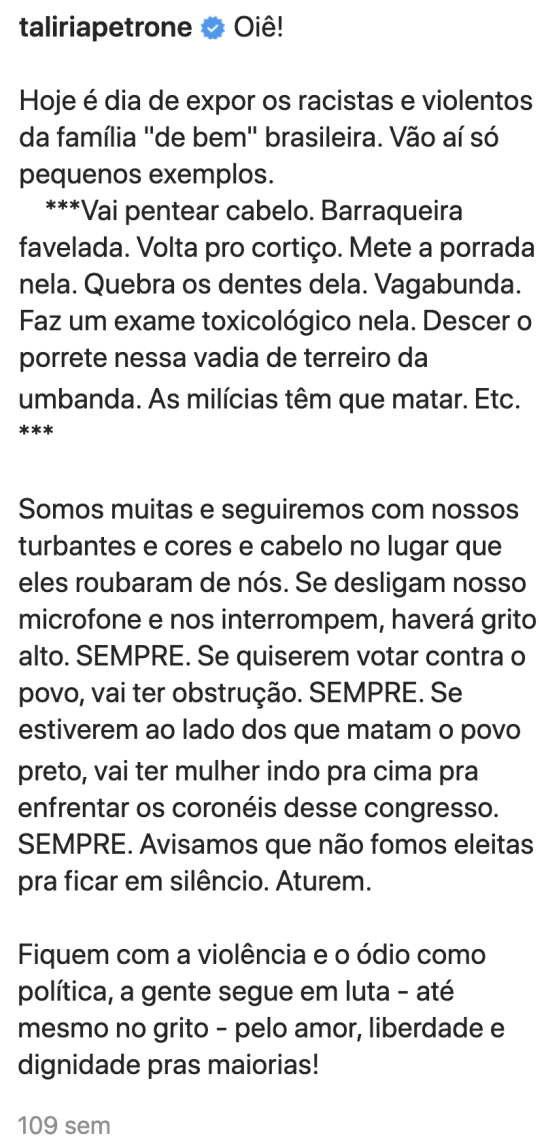

Figura 1 - Postagem feita pela deputada Talíria Petrone Fonte: Petrone, 2019.

Na sequência, a deputada apresentou, em carrossel, prints de postagens no Twitter e no Instagram, tanto de anônimos quanto de parlamentares da mesma legislatura. Por conta das identidades e do teor violento, racista e misógino dos conteúdos, optamos por reproduzir apenas alguns deles, não identificando os agressores. Consideramos, ainda, que o resumo apresentado no próprio post da parlamentar nos permite analisar os significados do "vocabulário, discursos, imagens, gestos, ações e olhares" (KILOMBA, 2020, p. 
78) das ofensas e ameaças dentro da herança escravagista colonial. Abaixo, reproduzimos integralmente o conteúdo de algumas dessas publicações.

Vai pentear este teu cabelo sua favelada. Como pode ter pessoas que elegem uma imoral desta para Deputada Federal?? Só sendo Analfabeto e desinformado de tudo

Maconheira! Se veste igual uma velha em um terreiro de umbanda kkkkkkkkk muita maconha na cabeça desse 'ser'

Que zona esse plenário, mas já que é pra descer de nível, desse [sic] o porrete nessa vadia...melhor não eles são muitos momentos kkkk

Várias postagens, inclusive algumas cujo conteúdo preferimos não reproduzir, se referem explicitamente a um suposto comportamento sexual desviante da parlamentar, apoiado exclusivamente nas fantasias brancas sobre a sexualidade das mulheres negras. Como afirma Kilomba, são expressões que identificam pessoas negras com práticas consideradas sujas, mas também excitantes. Aqui vale a pena lembrarmos como alguns termos permanecem no vocabulário racista amparado na herança colonial brasileira. É o caso da expressão "negra nojenta", adjetivo que no dicionário Aurélio recebe como uma das suas definições: "repulsivo; que causa nojo, asco; que provoca repugnância: cheiro nojento". No entanto, como lembra Gonzales,

O que a gente já sabe sobre a vida sexual da rapaziada branca até não faz muito: iniciação e prática com as crioulas. [...]. Quando chegava na hora do casamento com a pura, frágil e inocente virgem branca, na hora da tal noite de núpcias, a rapaziada simplesmente brochava. Já imaginaram o vexame? E onde é que estava o remédio providencial que permitia a consumação das bodas? Bastava o nubente cheirar uma roupa de crioula que tivesse sido usada para 'logo apresentar os documentos'. (GONZALEZ, 2020, p. 87)

Lélia concluirá, portanto, que "fica fácil entender quando xingam a gente de negra suja" (GONZALEZ, 2020, p. 87). Ou seja, foi a partir de práticas de incitação sexual dos homens brancos com o cheiro das mulheres negras escravizadas, costume "tão comum nos intramuros da casa-grande" (p. 86), que o cheiro das mulheres negras passou a ser "a chamada catinga de crioula" (p. 86). Mesmo não sabendo a origem da expressão, a sua utilização é sempre com o intuito de ridicularizar, num vocabulário que atualiza o imaginário colonial.

Já expressões como 'favelada', 'volta pro cortiço' ou 'volta para a senzala' reproduzem o desejo de manutenção da ordem escravocrata, que aparta pessoas pretas e pobres dos espaços de poder. Nesse cenário colonial, a Câmara se associa à Casa Grande. Essa associação traz a Câmara, ambiente público que deveria ser a casa do povo, para o ambiente doméstico da Casa Grande, no qual a Talíria, uma mulher negra, jamais poderia sentar-se à mesa ou visitar a sala em ocasião de visita (XAVIER, 2012).

As expressões evidenciam, portanto, o quanto os padrões das relações do período escravocrata permanecem vivos no nosso cotidiano, em uma prática de empenho contínuo da branquitude racista para permanecer acreditando que a Câmara, assim como as instituições políticas do país, ainda são a Casa Grande escravagista. E com isso utilizam essas instituições políticas para “mandos e desmandos" (FRANCO, 2018) que garantem a continuidade dos seus interesses privados a partir da manutenção de privilégios econômicos, sociais e culturais.

Desse modo, tal expressão, ao ser direcionada à Talíria, aponta um comportamento social que expressa o compromisso da elite branca e racista brasileira na manutenção da herança escravocrata na estrutura da vida cotidiana, que confina as mulheres negras na subalternidade.

Já a expressão "vai pentear esse cabelo", recupera uma associação colonial entre o cabelo natural das pessoas negras e a condição subalterna. Kilomba enfatiza que no período colonial, "mais do que a cor de pele, o cabelo tornou-se a mais poderosa marca de servidão" (2020, p. 126-127). Nesse projeto de 
sociedade fundada nas bases ideológicas do racismo sobre as pessoas negras, a incorporação de tais sujeitos às estruturas formais se dá em termos de branqueamento. "Pentear o cabelo" - alisar, melhor dizendo significa o reconhecimento de que para ser aceito em determinados espaços é necessário, literalmente, tornar-se branca, um processo violento de ruptura dos laços que unem essas mulheres às suas comunidades e causa uma perda de identidade.

Esse histórico de violência, em que a classificação do cabelo das pessoas negras como "cabelo ruim" é um dos sintomas, mobiliza as lutas políticas em todo o mundo pela afirmação da identidade negra e contra as agressões escamoteadas em expressões naturalizadas no senso comum. Frases como "que cabelo é esse?" escancaram o racismo cotidiano e interseccional do qual as mulheres negras são vítimas, mesmo após os 132 anos da oficialização do fim do regime escravocrata no Brasil. As relações de base escravocrata ainda permeiam o tecido social e cotidianamente operam para desumanizar as pessoas negras.

Kilomba lembra que o termo "cotidiano" refere-se ao fato de que as experiências com o racismo não são eventos pontuais na vida das pessoas negras. Nesta perspectiva, podemos perceber como as ameaças e xingamentos contra a parlamentar "desde o início do mandato, numa Câmara majoritariamente conservadora, com muitos representantes da extrema direita" (PETRONE; JESUS; MALUNGUINHO; FRANCISCO et al., 2020) não são um "ataque único" ou um "evento discreto", mas sim uma "exposição constante ao perigo", um "padrão contínuo de abuso" que se repete incessantemente ao longo da sua biografia. Ou seja, uma violência política a partir de "atos sistêmicos com o objetivo de excluir pessoas ou grupos sociais da esfera pública de debate e decisão. Em nossa sociedade [brasileira], essa violência tem fundamentos raciais e de gênero" (PETRONE; JESUS; MALUNGUINHO; FRANCISCO et al., 2020).

A parlamentar Renata Souza relata que, na Alerj, os reflexos do machismo e racismo podem ser vistos nos gestos e ações do cotidiano, como as tentativas de impedir as deputadas Dani Monteiro e Mônica Francisco de usarem o elevador exclusivo para deputados, ou de desqualificar os discursos dessas parlamentares no plenário.

$\mathrm{Eu}$, por exemplo, ao enfrentar os detratores dos direitos humanos de forma incisiva e assertiva, sou adjetivada como 'metida', 'cheia de marra' e 'nariz em pé'. A fala destemida, ousada e afiada é considerada insolente para a branquitude que sempre submeteu as mulheres negras ao violento silêncio (SOUZA, 2020, p. 14).

Lélia Gonzalez argumenta que "o racismo se constituiu como a sintomática que caracteriza a 'neurose cultural brasileira'. Nesse sentido, veremos que sua articulação com o sexismo produz efeitos violentos sobre a mulher negra em particular" (GONZALEZ, 2020, p. 76). A deputada federal Talíria Petrone revela que os "ataques sistemáticos nas redes sociais, em que [é] chamada de 'vagabunda', em que dizem que se [a] encontrarem na rua vão 'meter uma bala na minha cara', para eu 'voltar para senzala"' (JANSEN, 2020) reafirmam o grau de barbárie a que estão expostas as mulheres negras na política institucional comprometidas com a luta por direitos humanos no país.

O dito 'meter uma bala na minha cara' é uma expressa ameaça de morte, com requinte de crueldade, feita publicamente à Talíria por meio da rede social, evidenciando as opressões interseccionais sobre as mulheres negras parlamentares. Pois o que levaria alguém a querer disparar uma bala de arma de fogo no rosto de outra pessoa? Recorremos ao senso comum para traduzir o significado do termo 'bala' no dito 'meter uma bala na minha cara', que é usado e culturalmente reconhecido como uma ameaça de disparo por arma de fogo contra a face de uma parlamentar eleita. E, nesse cenário, Talíria ressalta que:

Ataques a mulheres e corpos negros não devem ser naturalizados em nenhum contexto, inclusive no exercício de mandatos parlamentares e em processos eleitorais. A população não deve ter como mensagem a ideia de que o poder não deve ser ocupado por aquelas que 
representam mais da metade da população, e não deve existir nenhum espaço institucional no qual as mulheres sejam proibidas ou desencorajadas de estar. (PETRONE, 2020)

Assim como descortinamos o sentido de expressões como 'voltar para a senzala', 'volta para a favela', nesse momento nos concentraremos na significação dos termos 'vadia', 'vagabunda'. O dicionário Dício diz que vagabunda é um "substantivo feminino [Informal] Pej. Aquela que possui modos de vida considerados amorais, embora não viva da prostituição" (c2021). Com base nesta definição, observamos novamente a expressão do machismo sobre a sexualidade da mulher e "o uso da condição feminina como uma coisa degradável”, como afirmou a ex-presidenta Dilma Rusself (TORRE..., 2019). Por todas as violências proferidas contra Talíria é possível descortinar e aprofundar a dimensão e complexidade de como "as ideologias racista e sexista permeiam a estrutura social a tal ponto que se tornam hegemônicas, ou seja, são vistas como naturais, normais e inevitáveis" (COLLINS, 2019, p. 35). É nesse sentido, portanto, que Talíria afirma que "a luta contra a violência política de gênero e raça é uma tarefa de todas e todos nós!" (PETRONE, 2020). A deputada federal complementa, ainda, que:

O Brasil é fundado sob o mito da democracia racial. Desde a escravização de nossos antepassados, sabemos que a violência é o recurso que o poder colonial aciona para manter corpos subalternizados. Essa violência não precisa sequer ser justificada, pois corpos negros são entendidos como menos que humanos, como coisas, até hoje como propriedades - o que o genocídio da juventude negra confirma. Também temos uma longa história de ditaduras e de feroz repressão aos movimentos e levantes populares, mesmo nos períodos ditos democráticos.

Somadas, a força bruta e a violência institucional escancaram que, com o racismo, nunca houve democracia. (PETRONE, 2020)

Ao mesmo tempo que todas essas violências mantêm viva a base das relações escravocratas, ou seja, a exploração da população negra e, dentro desse grupo social, da mulher negra, também atualizam as imagens de controle das mulheres negras na sociedade e consequentemente na política. De acordo com Patrícia Collins (2019), no contexto dos Estados Unidos, nas décadas de 1980 e 1990, as imagens de controle da mammy, matriarca, rainha da assistência social e dama negra foram evoluindo em conjunto com os esforços continuados para cortar gastos sociais com a população negra da classe trabalhadora e limitar ações afirmativas voltadas para ela. Da mesma forma, operaram para desqualificar sua fala e suas demandas. No Brasil, o estereótipo mais bem-acabado dessa tentativa de silenciamento é a imagem de controle da mulher barraqueira, aquela que não é séria, nem merece respeito, por isso, não deve ser ouvida.

Não raramente, pela sua fala incisiva e em tom assertivo, a parlamentar Talíria Petrone é classificada como barraqueira, em exercício da atividade parlamentar, em variadas ocasiões. Toda vez que é feita tal associação, vinculando a fala da Talíria ao sentido de barraqueira, é acionado no imaginário cultural um complexo de sentidos e significados, resultando no objetivo maior que é descredibilizar o que diz uma deputada federal eleita, nos moldes da democracia vigente.

Observa-se que outras expressões racistas, presentes nas ofensas e xingamentos contra a deputada, também são carregadas de imagens de controle, como 'volta pra senzala', ativando no imaginário coletivo a ideia da negra atrevida, que não sabe qual é o ‘seu lugar'. Já na expressão 'que cabelo é esse?' a agressão racista é feita com a intenção de ridicularizar os cabelos das pessoas pretas, e contém uma tentativa de dominação cultural. Estas são algumas das razões pelas quais Patrícia Collins defende que devemos estar vigilantes com a operacionalização das imagens de controle e seus efeitos sobre as mulheres, especialmente sobre as mulheres negras.

Quando Talíria relata as ameaças de 'meter uma bala na minha cara' ela evidencia por outra ótica a desumanização da mulher negra e as tentativas de controle sobre sua vida na sociedade brasileira. Com base nessas evidências, compreende-se um processo de reatualização desse imaginário de controle de corpos, 
perfis, cabelos, falas, roupas e identidades, a partir do discurso político, em uma tentativa de validar ou invalidar as pessoas aptas para ocupar um cargo político.

\section{VIOLÊNCIA E INTERSECCIONALIDADE}

Quando falamos sobre as violências contra a parlamentar Talíria Petrone, observamos que não são todas as mulheres que estão expostas ao mesmo nível de violência. A misoginia, conforme viemos argumentando, é uma das características da política institucional brasileira. Mas é preciso reconhecer que são as mulheres negras o alvo prioritário dessa violência que se dá em termos simbólicos (BOURDIEU, 2004), mas também, literalmente, na pele.

Renata Souza afirma que o assassinato de lideranças políticas femininas é pouco visibilizado e problematizado na mídia, sobretudo no Brasil. Por isso, é importante diferenciar os tipos de violência a que as mulheres estão sujeitas no exercício de seus mandatos. O racismo no Brasil é crime, previsto na Lei $\mathrm{N}^{\circ}$ 7.716, de 5 de janeiro de 1989. Outros crimes se somam aos ataques vistos à deputada Talíria: ameaça - Art. 147 do Código Penal - e assédio sexual - previsto no Art. 216 do Código Penal. Apesar disso, seus agressores nunca foram penalizados.

Embora todas as situações sejam gravíssimas, pouco se reconhece essa violência como crime, justificando a adoção de medidas protetivas. As agressões são dirigidas às mulheres pelo simples fato de serem mulheres e estarem exercendo o poder dentro de uma estrutura patriarcal. Nesses espaços, elas são aceitas como uma concessão do poder branco masculino, e desde que obedeçam à ordem estabelecida, seja por negociação ou por pressão direta.

Lugones (2008) reitera que ainda hoje nos identificamos a partir da raça, o que demonstra que a herança colonial persiste no imaginário. Nesse sentido, o Brasil é um país que insiste em negar a racialização das pessoas negras, ao passo que mantém no cotidiano os traços característicos da tradição escravista.

Se gênero e raça são uma ficção colonial, como nos aponta Lugones (2008), mulheres e homens são iguais, bem como pessoas de quaisquer etnias. Neste sentido, cabe perguntar por que mulheres não são bem recebidas e sofrem com a violência de raça e gênero. Partindo da perspectiva da professora Lugones (2008), compreendemos que há diferentes grupos de mulheres, com especificidades próprias, e que para algumas delas há o cruzamento de diversos tipos de violência, como gênero, raça, sexualidade e classe social. Esse cruzamento que já tinha sido mapeado por Lélia Gonzalez na década de 1980 foi, posteriormente, nomeado como interseccionalidade (CRENSHAW, 1991), conceito que expressa a sobreposição de opressões.

$\mathrm{Na}$ perspectiva de Oyěwùmí (2004), é possível inferir que as instituições jurídicas, financeiras e políticas formam-se a partir desse entendimento da localização das mulheres na ordem social, associadas ao doméstico e ao cuidado da família nuclear ocidental. Além de posicionar as mulheres na ordem social ocidental, tal orientação também condiciona os comportamentos esperados das mulheres, bem como as penalizações para todas as que descumprirem essa ordem social.

Nesse fluxo, são poupadas de violências e crimes as mulheres que seguem a ordem do poder patriarcal e são herdeiras do patrimônio político de seus pais e maridos. Mulheres como Talíria, que provocam fissuras na ordem racista/patriarcal precisam ser descredibilizadas, paralisadas e silenciadas. O feminicídio de Marielle Franco é a expressão máxima dessa lógica. Conforme Renata Souza, "em todos os ritos nas casas legislativas, há olhares e expressões corporais ameaçadoras, os nossos corpos negros são tratados como invasores que devem ser anulados" (SOUZA, 2020, p. 13).

Esse cenário de cultura do medo direcionado às mulheres negras é uma explícita reação estratégica para impedir a ocupação desses espaços políticos por pessoas que contrariem a ordem estabelecida e ameacem os interesses de gênero, raça e classe. Assim, quanto menos diversas forem as casas legislativas do país, menores serão os conflitos e a oposição para a política neoliberal e, consequentemente, para a defesa dos 
interesses privados desses agentes, que utilizam o legislativo como suporte para seus negócios na vida social, no campo e na cidade.

Mas, como argumentamos, a pena para quem ultrapassa as fronteiras é diferente conforme a posição dessas pessoas na matriz de opressão. Basta lembrar que, segundo o Atlas da Violência de 2019 (INSTITUTO DE PESQUISA ECONÔMICA APLICADA; FÓRUM BRASILEIRO DE SEGURANÇA PÚBLICA, 2019), a taxa de feminicídios entre mulheres negras aumentou 60\%, em uma década (2007-2017), enquanto entre as brancas subiu $1,7 \%$. Nesse cenário de riscos, trauma e adoecimento é que devem ser analisados os episódios de racismo cotidiano e interseccional contra parlamentares negras. Portanto, queremos destacar exatamente essa vulnerabilidade dessas mulheres no exercício de sua atividade na política institucional, resultado de um país racista que investe na supremacia branca e no sistema capitalista no seu nível mais ofensivo.

Não custa lembrar que muitos desses episódios são configurados como crimes, portanto, passíveis de punição. No entanto, nem as plataformas se responsabilizam por esses ataques racistas e misóginos, nem o Estado pune de forma célere seus agressores. As consequências têm sido, como argumentamos, um volume e uma intensidade de violência não assimiláveis pelas vítimas, o que produz uma realidade traumática.

\section{CONCLUSÃO}

O racismo e o sexismo na política são uma ameaça ao bem-estar físico e mental das mulheres em sua atividade. Na perspectiva que analisamos, eles constituem um tipo de violência que excede a sua capacidade de reação, pelo choque intenso que produzem, pela fragmentação que operam e por recolocarem suas vítimas de volta à cena colonial. Reúnem, portanto, os três elementos clássicos do trauma: o choque violento; ruptura da relação com a sociedade; e rememoração de um evento que ocorreu no passado. Suas consequências, como apontamos, deixam tanto a dor física (soma) quanto uma cicatriz psíquica de difícil reparação.

A eclosão desta violência, em episódios de racismo cotidiano e interseccional, ocorre não apenas na política, mas o fato de parlamentares se tornarem alvo de ataques e performances racistas revelam o quanto essa conduta foi normalizada na sociedade. São crimes, que, como mostramos, começam na tribuna e extravasam para as redes sociais digitais à luz do dia e sem constrangimentos. Numa sociedade em que a saúde e a integridade física de parlamentares em exercício do seu mandato não são consideradas essenciais, não se pode falar em democracia.

Tampouco se pode usar o argumento da liberdade de expressão para justificar a passividade das plataformas e da justiça diante da flagrante violação da lei e dos princípios democráticos. O direito à saúde, assegurado pela Constituição, neste caso pode ser visto como medida para avaliar a qualidade da democracia. Quando as mulheres pretas na política são vítimas de ações conscientemente impetradas para lhes causar dano físico e emocional, é a democracia que está doente.

\section{REFERÊNCIAS}

A REPRESENTAÇÃO feminina e os avanços na legislação. Agência Câmara de Notícias, Brasília, DF, 15 out. 2018. Notícias. Disponível em: https://www.camara.leg.br/noticias/546180-a-representacao-feminina-eos-avancos-na-legislacaol. Acesso em: 08/03/2021.

BANCADA feminina na Câmara sobe de 51 para 77 deputadas. Agência Câmara de Notícias, Brasília, DF, 8 out. 2018. Política e Administração Pública. Disponível em: https://www.camara.leg.br/noticias/545897bancada-feminina-na-camara-sobe-de-51-para-77-deputadas/. Acesso em: 8 mar. 2021. 
Reciis - Revista Eletrônica de Comunicação, Informação \& Inovação em Saúde, Rio de Janeiro, v. 15, n. 2, p. 333-345, abr./jun. 2021 [www.reciis.icict.fiocruz.br] e-ISSN 1981-6278

BOURDIEU, Pierre. A economia das trocas simbólicas. São Paulo: Perspectiva, 2004.

COLLINS, Patricia. Pensamento feminista negro: conhecimento, consciência e a política do empoderamento. São Paulo: Boitempo, 2019.

CRENSHAW, Kimberle. Mapping the margins: interseccionality, identity politics, and violence against women of color. Stanford Law Review, Stanford, v. 43, n. 6, p. 1241-1299, jul. 1991. DOI: https://doi. org/10.2307/1229039. Disponível em: https://www.jstor.org/stable/1229039. Acesso em: 14 jun. 2021

BARRETO, Raquel. Prefácio. In: DAVIS, Angela. Uma autobiografia. São Paulo: Boitempo, 2019. p. 11-13.

FRANCO, Marielle. Discurso: vereadora Marielle Franco. 8 mar. 2018. Disponível em: http://mail.camara. rj.gov.br/APL/Legislativos/discvot.nsf/5d50d39bd976391b83256536006a2502/cd266fdef87ea5fc8325824 a006d079d?OpenDocument. Acesso em: 8 mar. 2021.

GONZALES, Lélia. Racismo e sexismo na cultura brasileira. In: RIOS, Flávia; LIMA, Márcia (org.) Por um feminismo afro-latino-americano. Rio de Janeiro: Editora Zahar, 2020. p. 75-93.

HOOKS, bell. Erguer a voz: pensar como feminista, pensar como negra. São Paulo: Elefante, 2019.

INSTITUTO DE PESQUISA ECONÔMICA APLICADA; FÓRUM BRASILEIRO DE SEGURANÇA PÚBLICA. Atlas da violência 2019. Brasília, DF: Rio de Janeiro: São Paulo: Instituto de Pesquisa Econômica Aplicada; Fórum Brasileiro de Segurança Pública, 2019.

JANSEN, Roberta. Polícia identifica autor de ameaça à vereadora de Niterói, amiga de Marielle. Estadão Conteúdo, Rio de Janeiro, 28 mar. 2018. Notícias. Disponível em: https://noticias.uol.com.br/ultimasnoticias/agencia-estado/2018/03/28/policia-identifica-autor-de-ameaca-a-vereadora-de-niteroi-amiga-demarielle.htm. Acesso em: 05 nov. 2020.

KILOMBA, Grada. Memórias da plantação: episódios de racismo cotidiano. Tradução: Jess Oliveira. 3. ed. Rio de Janeiro: Cobogó, 2020.

LUGONES, María. Colonialidade e gênero. Tabula Rasa, Bogotá, n. 9, p. 73-101, jul.-dez., 2008. Disponível em: http://www.scielo.org.co/scielo.php?script=sci_arttext\&pid=S1794-24892008000200006\&lng=en\&nrm =iso\&tlng=es. Acesso em: 14 jun. 2021.

OYEWÙMí, Oyèrónké. Conceituando o gênero: Os fundamentos eurocêntricos dos fundamentos feministas e o desafio das epistemologias africanas. In: HOLLANDA, Heloisa Buarque de (Org.). Pensamento feminista hoje: perspectivas decoloniais. Rio de Janeiro: Bazar do tempo, 2020. p. 97-109.

PETRONE, Talíria. Oiê! Hoje é dia de expor os racistas e violentos da família "de bem" brasileira [...]. [S. I.], 18 maio 2019. Instagram: taliriapetrone. Disponível em: https://www.instagram.com/p/Bxm4O3zJYHC/. Acesso em: 16 jun. 2021.

PETRONE, Talíria; JESUS, Andréia de; MALUNGUINHO, Érica; FRANCISCO, Monica et al. A violência política contra parlamentares negras. Folha de S.Paulo, São Paulo, 18 nov. 2020. Opinião. Disponível em: https:// www1.folha.uol.com.br/opiniao/2020/11/a-violencia-politica-contra-parlamentares-negras.shtml. Acesso em: 8 mar. 2021.

QUIJANO, Aníbal. Colonialidade do poder, eurocentrismo e América Latina. In: LANDER, Edgardo (org). A colonialidade do saber: eurocentrismo e ciências sociais. Perspectivas latino-americanas. Buenos Aires: Colección Sur Sur, 2005. p.118-142.

SOUZA, Renata. Feminicídio Político: um estudo sobre a vida e a morte de Marielles. Cadernos de gênero e diversidade. Salvador, v. 6, n. 2, p. 7-20, abr.-jun. 2020. DOI: http://dx.doi.org/10.9771/cgd.v6i2.42037. Disponível em: https://periodicos.ufba.br/index.php/cadgendiv/article/view/42037. Acesso em: 14 jun. 2021.

SCHREIBER, Mariana. 'Irmã de vida' de Marielle e ameaçada de morte: a vereadora mais votada de Niterói. BBC Brasil, Brasília, DF, 18 mar 2018. Disponível em: https://www.bbc.com/portuguese/brasil-43453069. Acesso em: 8 mar. 2021. 
Reciis - Revista Eletrônica de Comunicação, Informação \& Inovação em Saúde, Rio de Janeiro, v. 15, n. 2, p. 333-345, abr./jun. 2021 [www.reciis.icict.fiocruz.br] e-ISSN 1981-6278

TORRE das donzelas. Direção de Susanna Lira e Nuno Godolphim. Rio de Janeiro: Modo Operante Produções, 2019. 1 vídeo (97 min).

VAGABUNDA. In: DÍCIO: DICIONÁRIO ONLINE DE PORTUGUÊS. [S. I.]: 7Graus, c2021. Disponível em: https://www.dicio.com.br/vagabundal. Acesso em: 17 jun. 2021.

XAVIER, Giovana; FARIAS, Juliana Barreto; GOMES, Flavio (org.). Mulheres negras no Brasil cravista e do pós-emancipação. São Paulo: Selo Negro, 2012. 